\section{RECENT CONTRIBUTIONS TO THE HISTORY OF DETONATING AGENTS 1}

III.

NOBEL has observed that if, instead of making use of the most explosive form of gun-cotton, or trinitrocellulose, a lower product of nitration of cellulose (the so-called soluble or collodion gun-cotton) is added to nitro-glycerine, the liquid exerts a peculiar solvent action upon it, the fibrous material becoming gelatinised while the nitro-glycerine becomes at the same time fixed, the two substances furnishing a product having almost the characters of a compound. By macerating only from 7 to 10 per cent. of soluble gun-cotton with 90 to 93 per cent. of nitroglycerine, the whole becomes converted into an adhesive plastic material, more gummy than gelatinous in character, from which, if it be prepared with sufficient care, no nitro-glycerine will scparate even by its exposure to heat in contact with bibulous paper, or by its prolonged immersion in water, the components being not easily susceptible of separation, even through the agency of a solvent of both. As the nitro-glycerine is only diluted with a small proportion of a solidifying agent which is itself an explosive (though a somewhat feeble one), this blasting gelatine, as Nobel has called it, is more powerful not only than dynamite, but also than the mixture of a smaller quantity of nitro-glycerine with the most explosive gun-cotton, as the liquid substance is decidedly the most violent explosive of the two. Moreover, as nitro-glycerine contains a small amount of oxygen in excess of that required for the perfect oxidation of its carbon and hydrogen constituents, while the soluble gun-cotton is deficient in the requisite oxygen for its complete transformation into thoroughly oxidised products, the result of an incoporation of the latter in small proportion with nitro-glycerine, is the production of an explosive agent which contains the proportion of oxygen requisite for the development of the maximum of chemical energy by the complete burning of the carbon and liydrogen, and hence this blasting gelatine should, theoretically, be even slightly more powerful as an explosive agent than pure nitro-glycerine.

That such is the case has been well established by numerous experiments, but although this blasting gelatine may be detonated like dynamite by means of small quantities of confined detonating composition, when it is employed in strongly-tamped blast-holes, or under cunditions very favourable to the development of great initial pressure, it behaves very differently from that material, or other solid though plastic preparations of nitroglycerine, if the attempt is made to detonate it when freely exposed to the air or only partially confined. It not only needs a much more considerable amount of strongly confined detonating composition than dynamite and similar preparations do, to bring about a detonation with it under those conditions; but when as much as fifteen or twenty grains of confined fulminate are detonated in direct contact with it, although a sharp explo. sion occurs, little or no destructive action results, and a considerable portion of the charge operated upon is dispersed in a finely-divided condition.

In comparing the effects of these nitro-glycerine preparations with each other and with compressed gun-cotton and preparations of it, by detonating equal quantities quite unconfined upon iron plates, the results appear to establish great superiority, in point of violence, of action, or destructive effect, of the more rigid explosive agents (the gun cotton preparations). Thus, employing iron plates $\mathrm{x}$ inch thick (supported upon an anvil with a central cavity), and $4 \mathrm{oz}$, of each material unconfined, the charges being all about the same diameter, exploded by detonators of equal strength, and simply resting upon the upper surface of the plate, compressed gun-cotton produced a considern' le indentation of the upper surface of the plate, and loris cracks in the lower surface; a species of nitrated gun-cotton, called tonite, produced a much shallower indentation, though still a very marked one, but did not crack the lower surface. Dynamite produced only a very slight impression upon the plate, and none could be detected by the eye on the plate upon which the blasting gelatine was exploded. The difficulties, brought out by past experience, which attend the contrivance of really comparative tests of the explo:ive power of such substances as those under discussion, is well exemplified by the foregoing results, which were influenced

1 Weekly Evening Lecture at the Royal Institution, Friday, March 2x, 1879. By Professor Abel, C.B., F.R.S. Revised by the Author. Continued frum p. 45 . to the maximum extent by the physical characters of the several substances when thus applied, in a perfectly unconfined condi. tion, so that the particles were free to yield to the force of the initiative detonation in proportion to their mobility. But, for this very reason, these experiments afford excellent illustration of the extent to which the development of detonation and the sharpness of its transmission through the mass is influenced not only by the inherent sensitiveness of the substance to detonation, but also by the degree of proneness of their particles to yield mechanically to the force of a blow as applied by an initiative detonation. Thus, although in comparing two substances of similar physical characters, compressed gun-cotton and compressed nitrated guncotton or tonite, the superiority of the pure compound over the mixture, in point of sharpness and violence of action, is well illustrated, a comparison of the result furnished by the weakest of the four explosive agents tried, viz., tonite, with that of the substance which should be superior to all the others in explosive force (i.e. the blasting gelatine) demonstrates the important in. fluence which the comparatively great rigidity of the mass in the one case exerts in favouring the completeness and sharpness of its detonation in open air, and the great disadvantage under which the other explosive is applied, arising out of the plastic and therefore readily yielding nature of the material. But if, by exposure to a moderate degree of cold, this plastic nitroglycerine preparation is made to freeze, its detonation upon an iron plate produces an indentation, as well as a destructive effect upon the lower surface of the plate, very decidedly greater than those furnished by the corresponding amount of pure com. pressed gun cotton. Similarly, the effect produced by the detonation of dynamite úpon a plate of the kind used, is but little inferior to that of gun-cotton, and decidedly greater than that of tonite, if it is employed in the frozen condition.

A series of experiments bas been made with cylinders of lead having a central perforation $\mathrm{I} \cdot 3$ inch in diameter extending to a depth of 7 inches and leaving solid metal beneath of a thickness ranging from 3.5 to 5.5 inches, according to the size of the cylinders used. These furnished results of considerable interest as illustrating the action of these several detonating agents. Charges of $\mathbf{I} \cdot 25 \mathrm{oz}$. of each explosive substance were used throughout the experiments, and were placed at the bottoms of the holes. By the detonation of the charges the cylindrical holes in the lead were enlarged into cavities of a pear shape (and sometimes approaching the spherical form) of various diameters; in some instances the metal was besides partially torn open in a line from the bottom of the charge-hole to the circumference of the lower face of the cylinder; and in the case of some of the gun-cotton charges, the fissure in the metal in this direction was complete, the base of the block being separated from the remainder, in the form of a cone. In the first place the portions of the holes above the charges were simply left open; in the subsequent experiments they were filled up to a level with the upper surface, with dry, fine, loose sand, 'or with water. The dimensions of the cylinders were increased in successive experiments until, in the case of every one of the explosives used, the mass of metal was sufficiently great to resist actual fracture at the base of the cylinder. Under the condition of these experiments, more or less considerable resistance being opposed to the mechanical dispersion of the plastic explosive substances, their detonation was greatly facilitated, though even then, the holes in the lead blocks being left open to the air, some amount of the blasting gelatine evidently escaped detonation; the widening of the upper part of the charge-hole, in experiments of this nature made with the gelatine, indicated that detonation was trans. mitted to small portions dispersed in the first instance and in the act of escaping from the block. In all the experiments, whether the holes were left open or filled with sand or water, the effect produced upon the base of the block by the detonation of compressed gun-cotton, was considerably more violent than with the other explosive agents, indicating a sharpness of action which was only shared by the blasting gelatine when used in a frozen state in one of these experiments. The dimensions of the cavities produced by the gelatine were, at the largest part, considerably greater than those produced by the dynamite and nitrated gun. cotton (tonite), and slightly greater than those of the gun-cotton charges; but in the latter, the fracture of the base of the cylinder gave rise in most of the experiments to an escape of force, so that in these cases the effects of the detonation could not be well compared by measurements of the cavities. When the gelatine was converted by freezing into a rigid mass its superiority in explosive force even over compressed gun.cotton 
was well illustrated; the base of the lead block was all but blown out, the cavity produced was considerably the largest, and the suddenness and violence with which motion was imparted to the water tamping caused the top of the block also to be blown off in the form of a cone.

The difficulties attending the application of blasting gelatine, in some directions in which explosive agents are applied, on account of the uncertainty attending the development of its explosive force, even with the use of a comparatively powerful detonator, unless it be very strongly confined, has led to attempts to reduce its non-sensitiveness to detonation by mixing it with materials intended to operate either by virtue of their compara. tively great sensitiveness or of their property as solies, of reducing the very yielding character of the substance, or in both ways.

Some of these attempts have been attended with considerable success. Thus the incorporation of about ro per cent. of the most explosive form of gun-cotton or trinitrocellulose, in a very finely divided state, with the gelatine, renders it so much more sensitive that it can be detonated with certainty in the open air by means of the strongest detonating cap now used for exploding dynamite. This effect appears to be less due to the comparative sensitiveness of gun-cotton to detonation than to the modification effected in the consistency of the material, which, though still plastic, offers decidedly greater resistance to a blow than the original gummy substance. The particles of hollow fibre of the gun-cotton appear also to have the effect of absorbing small quantities of nitro-giycerine which are less perfectly united with the soluble gun-cotton than the remainder, and which, existing as they do in somewhat variable proportions in the gelatine, have occasionally an objectionable tendency to exudation, if the incorporation of the ingredients has been less perfect than usual. The substance, when modified as described, has no longer that great adhesiveness which is exhibited by it in the original state, and which renders it less easy to manipulate.

Lastly, its explosive force appears to be in no way diminished by this modification of its composition; on the contrary, its superiority in this respect to compressed gun-cotton becomes more manifest, as demonstrated by some of the experiments with lead blocks, while its action partakes of that sharpness peculiar to the detonation of the rigid gun-cotton, as indicated by the fissure of that part of the metal situated beneath the charge. Finely divided cotton fibre has a similar effect to trinitrocellulose in modifying the physical character and increasing the sensitiveness to detonation of the blasting gelatine, but its explosive force is, of course, proportionately reduced with its dilution with an inert substance.

Nobel has made the interesting observation that an addition to the blasting gelatine of small proportions of certain substances rich in carbon and hydrogen, which are soluble in nitro-glycerine, such as benzol and nitro-benzol, increases to a remarkable extent the non-sensitiveness to detonation of the original material ; and this observation has led to experiments being conducted by engineer officers in Austria, with a view of endeavouring to convert the blasting gelatine into a material which should compete, as regards some special advantages in point of safety, with wet guncotton in its application to military and naval purposes, and especially as regards non-liability to detonation or explosion by the impact of rifle bullets. If boxes containing dry compressed gun-cotton are fired into from small arms even at a short range, the gun cotton is generally inflamed, but has never been known to explode. It is scarcely necessary to state that wet gun-cotton, containing even as little as I5 per cent. of water, is never inflamed under these conditions. On the other hand, dynamite is invariably detonated when struck by a bullet on passing through the side of the box, and blasting "gelatine, though so much less sensitive than dynamite, behaves in the same way in its ordinary as well as in the frozen condition. The Austrian experiments indicated that the gelatine when intimately mixed with only I per cent. of camphor, generally, though not invariably, escaped explosion by the impact of a bullet, but that when the proportion of camphor amounted to 4 per cent. the material was neither exploded nor inflamed, though, in the frozen state, it was still liable to occasional explosion. These results were considered indicative of a degree of safety in regard to service exigencies, approaching that of wet compressed gun-cotton. The camphoretted gelatine still labours, however, under the disadvantage of being readily inflammable and of burning fiercely, and consequently of giving rise, like dynamite and dry gun-cotton, to violent explosion, or detonation, if burned in con- siderable bulk. Moreover, the camphoretted blasting gelatine is so difficult of detonation by the means ordinarily applied that a large initiative charge of a specially violent detonating mixture is prescribed by the Austrian experimenters as being indispensable to its proper detonation.

The action of camphor and of other substances rich in carbon and hydrogen in reducing greatly the sensitiveness to detonation of the preparation of soluble gun-cotton and nitro-glycerine is not to be traced to any physical modification of that material produced by the addition of such substances, and no satisfactory theory can at present be advanced to account for it on chemical grounds.

The camphoretted gelatine, like Nobel's original gelatine itself, may be kept immersed in water for a considerable time without any important change; the surface of the mass thus immersed becomes white and opaque, apparently in consequence of some small absorption of water, but no nitro-glycerine is separated, and on re-exposure to the air the material gradually assumes once more its original aspect. It has consequently been proposed to render the storage of blasting gelatine comparatively safe by keeping it immersed in water till required for use, but the test of time is still needed to establish the unalterableness of the material under this condition.

There can be little question that this interesting nitro-glycerine preparation, either in its most simple form, or modified in various ways, by the addition of other ingredients, promises, by virtue of its great peculiarities as a detonating agent, to present means for importantly extending the application of nitro-glycerine to industrial purposes ; and it is not improbable that, through its agency, this most violent of all explosive agents at present producible upon a large scale may also come to acquire special value for important war-purposes.

It has been pointed out that the complete solidification, by freezing, of plastic preparations containing nitro-glycerine, such as dynamite and the blasting gelatine has the effect of facilitating the transmission of detonation throughout the mass under certain conditions of their applications, i,e, when they are either freely exposed to air or not very closely or rigidly confined. But while, under circumstances favourable to the detonation of these substances, when in the frozen state, their full explosive force is thus much more readily applied than when they are in their normal (thawed) condition, the frozen substances are less sensitive to detonation by a blow or an initiative detonation. On the other hand, if subjected to the rapid application of great heat (as for example by the burning of portions of a mass of the explosive substance itself), a detonation is mitch more readily brought about with the frozen material than if it be in its normal con. dition. Thus a package containing $50 \mathrm{lb}$. of cartridges of plastic dynamite, when surrounded by fire, burned away without any indication of explosive action; on subraitting $10 \mathrm{lb}$. of frozen dynamite to the same treatment, that quantity also burned without explosion, though at one time the combustion was so fierce as to indicate an approach to explosive action; but when the experiment was repeated on the same occasion with $15 \mathrm{lb}$. of frozen dynamite a very violent detonation took place after the material had been burning for a short time.

The following is offered as the most probable explanation of this result. When a mass of dynamite, as in these cartridges, is exposed to sufficient cold to cause the nitro-glycerine to freeze, it does not become uniformly hardened throughout, partly because of slight variations in the proportion of nitro-glycerine in different portions of the mixture composing the cartridge, and partly because unless the exposure to cold be very prolonged the external portions of the cartridges will be frozen harder or more thoroughly than the interior. It may thus arise that portions of only partially frozen or still unfrozen dynamite may be more or less com. pletely inclosed in hard crusts, or strong envelopes, of perfectly frozen and comparatively very cold dynamite. On exposure of such cartridges to a fierce heat very rapidly applied, as would result from the burning of a considerable quantity of the material, some portion of one or other of the cartridges would be likely to be much more readily raised to the igniting or exploding point than the remaining more perfectly frozen part in which it is partly or completely imbedded. If the ignition of this portion be brought about (which it will be with a rapidity proportionate to the intensity of heat to which the cartridge is exposed), the envelope of hard frozen dynamite by which it is still more or less completely surrounded and strongly confined, will operate like the metal envelope of a detonator, in developing the initial pressure essential for the sudden raising of the more readily in. 
flammable portion of the dynamite to the temperature necessary for the sudden transformation of the nitro-glycerine into gas, and will thus bring about the detonation of a portion of the cartridge, which will act as the initiative detonator to the remainder of the dynamite. On igniting separately, at one of their extremities, some dynamite cartridges which had been buried in snow for a considerable period, the lecturer has observed that, as the frozen material gradually burned away, very slight but sharp explosions (like the snapping of a small percussion cap on a gun nipple) occurred from time to time, portions of the frozen dynamite being scattered with some violence. It has come to his knowledge that small heaps of hard-frozen cartridges weighing altogether one pound have been detonated by igniting one cartridge which was surrounded by the remainder. These facts appear to substantiate the correctness of the foregoing explanation. They point to the danger: of assuming that, because dynamite in the frozen state is less sensitive to the effects of a blow or initiative detonation, than the thawed material, it may therefore be submitted without special care to the action of heat, for the purpose of thawing it. Instances of the detonation, with disastrous results, of even single cartridges of frozen dynamite, through the incautious application of considerable heat (as for example by placing them in an oven, or close to a fire), have been, and are still, of not unfrequent occurrence, even though Mr. Nobel has insisted upon the application of heat through the agency only of warm water, as the sole reliable method of safely thawing dynamite cartridges.

While the sensitiveness to detonation of air-dry gun-cotton remains unaffected by great reduction in temperature of the mass, and while in this respect it presents advantages over nitro-glycerine preparations, wet gun-cotton becomes very decidedly more susceptible to detonation when frozen. Thus the detonation of gun-cotton containing an addition of from ro to 12 per cent. of water is somewhat uncertain with the employment of 100 grains of strongly confined fulminate, and 200 grains are required for the detonation of the substance when containing 15 to 17 per cent. of water; but the latter in a frozen state can be detonated by means of thirty grains of fulminate, and fifteen grains are just upon the margin of the amount requisite for detonating, with certainty, frozen gun-cotton containing 10 to 12 per cent. of water.

The effects produced and products formed by the explosion of gun-cotton in perfectly closed spaces, both in the loose, and the compressed form, and by its detonation in the dry and the wet state, have been made the subject of study by Capt. Noble and Mr. Abel, the method of research pursued being the same as that followed in their published researches on fired gunpowder; results of considerable interest in regard to the heat of explosion; the pressures developed, and the products of explosion of dry and wet gun-cotton, bave been obtained, which are about to be communicated to the Royal Society.

It may briefly be stated that the temperature of explosion of gun-cotton is more than double that of gunpowder (being about $4,400^{\circ}$ C.); that the tension of the products of explosion, assuming the material to fill entirely the space in which it is fired, is considerably more than double that of the powder. products under the same conditions; that the products obtained by the explosion of dry gun-cotton are comparatively simple and very uniform under different conditions as regards pressure; that the products of detonation of $d r y$ gun-cotton do not differ materially from those of its explosion in a confined space, but that those furnished by the detonation of wet gun-cotton present some interesting points of difference. Messrs. Nobel and Abel are extending their investigations to the nitro-glycerine preparations.

The great advance which has been made within the last twelve years in our knowledge of the conditions which determine the character of the metamorphosis that explosive substances undergo, and which develop or control the violence of their action, finds its parallel in the progress which has been made in the production, perfection, and application of the two most promiment of modern explosive agents, nitro-glycerine and gun-cotton. Discovered at nearly the same time, less than forty years ago, the one speedily attained great prominence, on account of the apparent ease with which it could be prepared and put to practical use; a prominence short-lived, however, because to prac and somewhat rash, attempts to utilise it preceded the acquisition of sound and sufficient knowledge of its nature and properties. Even many years afterwards, when the difficulties attending its employment appeared to have been surmounted, the confidence of its most indefatigable partisans and staunchest friends received a rude shock, from which it needed the support of much faith and some fortitude to recover.

Meanwhile, the other substance, which now shares with it the honours of important victories won over gunpowder, continued to be generally regarded as a dangerous chemical curiosity, even for some time after its present position as one of the most important industrial products and useful explosive agents was being gradually but firmly secured for it, step by step, by the talent and untiring energy of a single individual.

Almost from the day of its discovery, the fortunes of guncotton continued to fluctuate, and much adversity marked its career, until at last its properties became well understood, and its position as a most formidable explosive agent, applicable on a large scale, with ease, great sinplicity, and with a degree of safety far greater than that as yet possessed by any other substance of this class, has now become thoroughly established. Since the lecturer last discoursed on the properties of guncotton, seven years ago, this material has attained a firm footing as one of the most formidable agents of defence and offence. For all military engineering operations, and for employment in submarine mines and torpedoes, compressed gun-cotton, stored and used in the wet condition, has become the accepted explosive agent in Great Britain; within the last five years upwards of $55^{\circ}$ tons have been manufactured for this purpose, and are distributed over our chief naval stations at home and abroad. Germany some years since copied our system of manufacture and use of gun-cotton; France has provided itself with a large supply for the same purposes, and Austria, where the acquisition of bitter experience of the uncertainty of gun-cotton in the earlier stages of history, naturally gave rise to a persistent scepticism regarding its present trustworthiness, appears now also about to adopt wet gun-cotton for military and naval uses.

But while the usefulness and great value of compressed guncotton in these important directions have been established, its technical application has made but slow progress as compared with that of the simple nitro-glycerine preparation known as dynamite, which, in point of cost of production and convenience for general blasting purposes, can claim superiority over compressed gun-cotton. Already in 1867 a number of dynamite factories, working under Nobel's supervision, existed in different countries; in that year the total quantity manufactured amounted to $I r$ tons; in another year the produce had risen to 78 tons: in 1872 it had attained to $I, 350$ tons. Two years afterwards the total production of dynamite was nearly trebled, and in 1878 it amounted to 6,140 tons.

There are as many as fifteen factories in different parts of the world (including a very extensive one in Scotland) working under the supervision of Mr. Nobel, the originator of the nitroglycerine industry, and some six or seven other establishments exist where dynamite or preparations of very similar character are also manufactured.

How far the rate of production of dynamite will be affected by the further development of the value of Nobel's new preparation, the blasting gelatine, it is difficult to foresee, but there appears great prospect of an important future for this very peculiar and interesting detonating agent.

It is hoped that the subjects dealt with in this discourse afford interesting illustration of the intimate connection of scientific research with important practical achievements.

\section{UNIVERSITY AND EDUCATIONAL INTELLIGENCE}

DR. CARPENTER, Registrar of the University of London, announced his retirement from that office at the annual meeting of Convocation on Tuesday. A unanimous vote was passed, recognising his long and valuable services in the post which he had so long held.

THE recent retirement of Prof. Balfour from the Chair of Botany at Edinburgh has given rise to two changes in the Scottish professoriate. As his successor, our readers know, the Curators have appointed Dr. Alexander Dickson, the able Professor of Botany in the University of Glasgow. The botanical class has always been popular at Edinburgh, Dr. Balfour's students having recently numbered, we believe, upwards of 350 . The class-room of the new professor, also, is so crowded that many of the auditors can hardly find standing-room, large number having been unable even to gain admission. Prof. Dickson is 